\title{
Pediatric upper gastrointestinal bleeding in children: etiology and treatment approaches
}

\author{
Esra Polat $^{1^{*}}{ }^{\left(\text {Nevzat Aykut Bayrak }^{2}{ }^{\circledR}, \text { Günsel Kutluk }^{1}{ }^{\circledR} \text {, Hasret Ayyıldız Civan }\right.}{ }^{(\mathbb{1}}$ \\ 'Department of Pediatrics, Division of Pediatric Gastroenterology, Health Sciences University, Kanuni Sultan Süleyman \\ Training and Research Hospital, Istanbul, Turkey \\ 2Department of Pediatrics, Division of Pediatric Gastroenterology, Health Sciences University, Zeynep Kamil Maternity and \\ Children's Training and Research Hospital, Istanbul, Turkey \\ ${ }^{3}$ Department of Pediatrics, Division of Pediatric Gastroenterology, Health Sciences University, Bakırköy Dr Sadi Konuk Training \\ and Research Hospital, Istanbul, Turkey
}

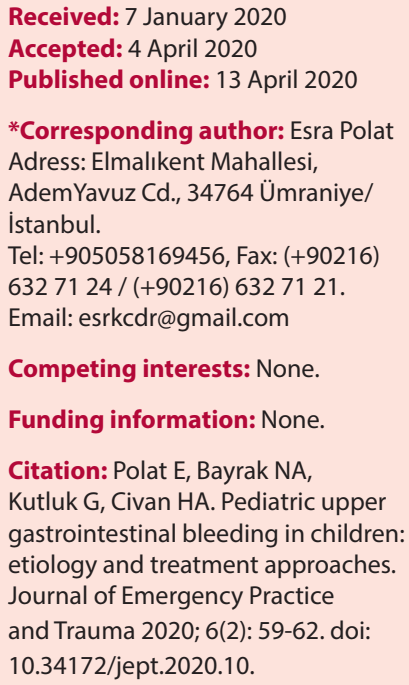

\begin{abstract}
Objective: Upper gastrointestinal bleeding (UGB) is one of the most important and serious cause of emergency admission in childhood. The aim of the study was to evaluate the etiological factors and the treatment approaches in patients with UGB.

Methods: In this retrospective study, children with UGB admitted to emergency clinics of Istanbul Health Sciences University Kanuni Sultan Suleyman Research and Training Hospital, Istanbul Bakirkoy Sadi Konuk Research and Training Hospital and Diyarbakir Children's Hospital were evaluated between January 2014 and August 2017.

Results: Of the 198 children, $14.6 \%$ had non-steroid anti-inflammatory drug (NSAID) history, and $12.6 \%$ had chronic liver disease. We detected esophagitis, esophagus varices and peptic ulcer with upper gastrointestinal endoscopic evaluation $(47 \%, 11.1 \%, 18.1 \%$, respectively). Helicobacter pylori was found in $61.6 \%$ of patients. Endoscopic therapeutic procedures (band ligation therapy, sclerotherapy, and adrenaline injection) were appied in $11.1 \%$ of patients. Eighty-four (42.4\%) patients were hospitalized, and erythrocyte transfusion (ET) was ordered in $29(14.6 \%)$ patients.

Conclusion: Approximately in $20 \%$ of the pediatric patients, the source of gastrointestinal bleeding is the upper gastrointestinal system. The cause of UGB varies with age. Appropriate diagnostic and therapeutic approaches are very important for management and to reduce mortality.

Keywords: Upper gastrointestinal bleeding, Etiology, Treatment, Child
\end{abstract}

\section{Introduction}

Gastrointestinal bleeding originating from the upper segment of the Treitz ligament is defined as upper gastrointestinal bleeding (UGB). UGB is one of the most important causes of pediatric emergencies (1). In France, the annual frequency of childhood UGB was found as 1 to 2 in 10000 (2). The rate of hospitalization to the pediatric intensive care unit was found to be $0.4 \%$ - $1.6 \%$ due to severe UGB $(3,4)$. The mortality rate for UGB was reported between $5 \%$ and $21 \%$ in children (5). Besides, diagnosis and treatment are challenging for pediatric gastroenterologists. Approximately, $6.5 \%-25 \%$ of gastrointestinal bleeding in children originates from the proximal of Treitz ligament (6). The etiology varies by age and the causes substantially overlap (5). Detailed clinical history, rapid evaluation, appropriate medication, timely endoscopic examination, and appropriate treatment for the cause are important for UGB management (7).
In our country, we do not have enough demographic data about childhood UGB. Our objective was to assess the patients who were admitted to the emergency clinic for UGB in terms of etiological and treatment modalities.

\section{Methods}

This was a multicenter retrospective cross-sectional study. After approval from the ethics committee (Istanbul Health Sciences University, Umraniye Research and Education Hospital-14126/22.06.2018), consecutive children with UGB admitted to three tertiary center from Istanbul were evaluated between January 2014 and August 2017. Demographics of patients, symptoms, biochemistry, diagnostic and therapeutic data were obtained from patient files and hospital electronic database. Serum hemoglobin levels, hospitalization periods, erythrocyte transfusion (ET) requirement, endoscopy timing, upper endoscopic findings and endoscopic procedures were all 
recorded.

If the patient's serum hemoglobin value was found below 7 $\mathrm{g} / \mathrm{dL}$, or if the serum hemoglobin value dropped more than $2 \mathrm{~g} / \mathrm{dL}$ within 1 hour, we performed ET administration. The exclusion criteria were: children with cerebral palsy, bleeding secondary to corrosive exposure, and history of previous upper gastrointestinal system surgery. A computer software program (IBM SPSS, version 20, IBM Corp., New York, USA) was used for data analysis. The distribution of the parameters was evaluated using the Shapiro-Wilk test. Continuous variables are presented as mean \pm standard deviation (SD). Categorical variables are presented as numbers and percentages. Student's $t$ test was used for comparing two groups with a normal distribution; the Mann-Whitney $U$ test was used for comparing two groups with no normally distributed parameters. In order to compare qualitative data, we used chi-square test. Also, to compare the changes between the groups, repeated measure analysis of variance test (ANOVA) was applied. Pearson's correlation analysis was used to examine the correlations between metric variables, while Spearman's rho correlation analysis was used for ordinal variables. The $P$ values $<0.05$ was considered as statistically significant.

\section{Results}

According to Table 1, 198 children (50.5\% males, mean age $=9.42 \pm 5.3$ years) were admitted to the emergency department with the complaint of bleeding. Twenty-nine children had a history of non-steroid anti-inflammatory drug (NSAID) use. Esophagitis, esophageal varices and peptic ulcers (PU) were determined respectively in 93 (47\%), $22(11.1 \%)$ and $36(18.1 \%)$ patients. The corpus, antrum, and bulbus localized PU were identified as $2.5 \%$, $8.5 \%, 7.1 \%$, respectively. H. pylori was pathologically identified in 122 patients. The $H$. pylori frequency was identified according to the localization and it was as follows; antrum $46.4 \%$, corpus $25.3 \%$ ( $P<0.05$, Table 2$)$.

History of chronic liver disease was identified in $12.6 \%$ of patients. In 29 (14.6\%) patients, ET was performed. Octreotide infusion was ordered in twenty cases (10.1\%), and endoscopic therapeutic approach was performed in $22(11.1 \%)$ patients, including band ligation $(n=5)$, sclerotherapy $(n=7)$, and adrenaline injection $(n=10)$. The rate of therapeutic interventions was significantly higher in esophageal varices or bulbar peptic ulcer $(P<0.01)$. The need for interventional therapeutic endoscopy was higher in patients with $H$. pylori-associated ulcers than non- $H$. pylori patients $(P<0.01$, Table 2$)$.

ET requirement increased in patients who had both melena and hematemesis compared to the patients who had only melena or hematemesis $(P<0.001)$. Eighty-four $(42.4 \%)$ patients were followed up by hospitalization in the pediatric gastroenterology service, mean time of hospital stay was $2.73 \pm 1.18$ days. The need for ET was correlated with hospital stay $\left(\mathrm{r}^{2}=0.68, P<0.01\right)$.
Table 1. Demographic, clinical and procedural characteristics of the study group

\begin{tabular}{|c|c|}
\hline Variable & \\
\hline Age $(y)$, Mean $\pm S D$ & $9.4 \pm 5.3$ \\
\hline Gender (male ) & 50.5 \\
\hline \multicolumn{2}{|l|}{ Symptoms, No. (\%) * } \\
\hline Vomiting & $98(49.5)$ \\
\hline Abdominal pain, №. (\%) & $93(46.9)$ \\
\hline Fever & $76(38.3)$ \\
\hline Cough & $44(22.2)$ \\
\hline Epigastric pain & $39(19.7)$ \\
\hline Rash & $15(7.5)$ \\
\hline Dysphagia & $15(7.5)$ \\
\hline Weight loss & $12(6.1)$ \\
\hline \multicolumn{2}{|l|}{ Type of bleeding, No. (\%) } \\
\hline Hematemesis & $126(63.6)$ \\
\hline Melena & $41(20.7)$ \\
\hline Both & $31(15.6)$ \\
\hline \multicolumn{2}{|l|}{ Risk factors, No. (\%) } \\
\hline Ibuprofen use & $29(14.6)$ \\
\hline Antibiotic use & $22(11.1)$ \\
\hline Chronic liver disease history & $25(12.6)$ \\
\hline Previous bleeding episode & $2(1.0)$ \\
\hline \multicolumn{2}{|l|}{ Endoscopic findings, No. (\%) } \\
\hline Esophagitis & $93(46.9)$ \\
\hline Esophageal varices & $22(11.1)$ \\
\hline Peptic ulcer & $36(18.1)$ \\
\hline in corpus & $5(2.5)$ \\
\hline in antrum & $17(8.5)$ \\
\hline in bulbus & $14(7.1)$ \\
\hline Helicobacter pylori presence, №. (\%) & $122(61.6)$ \\
\hline \multicolumn{2}{|l|}{ Interventions, No. (\%) } \\
\hline Erythrocyte transfusion & $29(14.6)$ \\
\hline Octreotide infusion & $20(10.1)$ \\
\hline Endoscopic & $22(11.1)$ \\
\hline Band ligation & $5(2.5)$ \\
\hline Sclerotherapy & $7(3.5)$ \\
\hline Adrenaline injection & $10(5.1)$ \\
\hline Hospitalization, No. (\%) & $84(42.4)$ \\
\hline Duration of hospitalization (days) & $2.73 \pm 1.18$ \\
\hline
\end{tabular}

* Some patients had more than one symptom.

\section{Discussion}

This study investigated the demographic and treatment characteristics of patients with upper GI bleeding in the childhood in Turkey. Findings showed that upper GI bleeding was the cause of $7 \%$ of gastroscopies performed in the participating centers. Major risk factor was NSAID use in $14.6 \%$, and peptic ulcer related bleeding was $18.1 \%$. In the two studies conducted in Israel and Japan, the widespread reasons of UGB were expressed as PU, esophagitis and gastritis (6,7). In our series, the most 
Table 2. Helicobacter pylori frequency by localisation and $\mathrm{Hp}$ association with ulcer in interventional procedures

\begin{tabular}{|c|c|c|c|}
\hline & Hp positive (\%) & Hp negative (\%) & $P$ Value \\
\hline Helicobacter pylori frequency by localisation* & & & $<0.05$ \\
\hline Antrum & 46.4 & 53.6 & \\
\hline Corpus & 25.3 & 74.7 & \\
\hline Interventional therapeutic endoscopy requirement & & & $<0.01$ \\
\hline Ulcer association & 72.4 & 27.6 & \\
\hline
\end{tabular}

* Some patients had Helicobacter pylori positivity both in corpus and antrum.

common etiologies were esophagitis (47\%), peptic ulcer (18.1\%) and esophagus varices (11.1\%). Jafari et al found esophagitis in $15.9 \%$ of patients who underwent endoscopy due to UGB (8). Gimiga et al reported $4.85 \%$ ratio of esophageal varices and $14.56 \%$ esophagitis in UGB (9). The etiology of UGB differs according to variations in patient characteristics (4). In the American continent, major causes of UGB include PU (44\%), esophageal varices $(11 \%)$, hematemesis due to vomiting (1.2\%), and erosive esophagitis (0.6\%). Conversely, in the Middle East and Asia, bleeding from PU (24\%), viral hepatitis related varices $(23 \%)$, erosive esophagitis $(0.2 \%)$, and vomitingrelated hematemesis $(0.2 \%)$ comprise most of UGB cases (10). Our data represent that our patient characteristics are more similar to the American patients rather than the Asians.

A history of NSAID use was detected in 29 (14.6\%) of the UGB patients we evaluated. Kalyoncu et al reported the incidence of UGB in children under 2 years of age due to NSAID use as $54 \%$ (11). The existence of a relationship between UGB and NSAID use was defined as $34.5 \%$ and $\% 15.6$ in two different studies $(12,13)$.

We found peptic ulcer in 36 patients in total with the endoscopic evaluation we performed for the cause of UGB. Five of the peptic ulcers were in the corpus $(2.5 \%)$, 17 in the antrum (8.5\%) and 14 in the bulbus (1\%). Histopathological evaluation of the biopsies taken showed $H$. pylori positivity in 122 patients. In antral lesions, $H$. pylori infection was significantly higher than those of the corpus $(46.4 \%$ vs $25.3 \%, P<0.05)$. Gimiga et al expressed the frequency of $H$. pylori in patients evaluated for UGB as $36.9 \%$ (9). Usta and Urganci stated the frequency of $H$. pylori as $20.7 \%$, highlighting that there is no relationship between UGB and $H$. pylori (14).

The causes of UGB may vary among countries. UGB incidence is higher in underdeveloped or developing countries compared to developed countries (1). In an Indian study, varicose-related bleeding was reported to be a significant cause of UGB in patients over 2 years of age in developing countries (15). According to one study which stated that varicose veins and peptic ulsers are seen equally (23.4\% vs $23.6 \%$ ) as the cause of UGB in the middle east, on the contrary, peptic ulcer is more common in the west as the cause of UGB (43.5\%) (10).
The frequency of esophagitis observed in both eastern and western countries was found to be significantly lower in the same study. In this study, the rate of esophagitis found as the cause of UGB was 5\%. However, in our UGB series, we found esophagitis at a frequency of $47 \%$, and esophagus varices at a frequency of $11.1 \%$.

We realized that endoscopic therapeutic approaches were usually used for the chronic hepatic disease group $(P<0.05)$. In addition, the necessity to apply ET to patients was directly proportional to the length of hospital stay. Kim et al stated that 39 out of 55 patients with variceal bleeding admitted to the hospital had control of bleeding with band ligation. In the same study, 16 out of 55 patients required sclerotherapy for bleeding control. In the same study, 16 out of 55 patients required sclerotherapy for bleeding control (16). As stated in a study conducted in the United Kingdom, upper gastrointestinal endoscopy was performed in 19 out of 32 patients evaluated for UGB, esophagus varices were detected in 5 patients, and 4 of these patients required band ligation treatment (17).

In a large case series conducted by Banc-Husu et al interventional procedures were required for bleeding control in 15 out of 17 UGB patients. In this study, 6 patients were re-bleeded and surgery was performed in two of these patients since the bleeding could not be stopped. In the same study, 11 patients needed ET (6). It is stated that if the patient has both melena and hematemesis, then the need for ET may increase in the patient $(10,17)$. We found similar results in our study. In our patients, the ratio of need for ET was $14.9 \%$, and none of our patients needed a surgical procedure. In a pediatric emergency clinic in Ankara, the clinically prominent UGB rate was determined as $26.8 \%$, and PU and gastritis were reported as the most common cause. In this patient group, nasogastric tube insertion and antacid therapy application were emphasized more frequently (12). In a retrospective study conducted in China, the serum haemoglobin level was below $8 \mathrm{~g} / \mathrm{dL}$, serum haemoglobin level fell more than $2 \mathrm{~g} / \mathrm{dL}$, and hematochezia, pallor as well as confusion were considered as significant bleeding indicators. These findings are consistent with our results (18).

In our investigation, we did not have any patients who died due to UGB. In a retrospective study in North America, mortality was associated with the fact that UGB patients 
received octreotide in the first 2 days of their admission to the hospital and did not receive proton pomp inhibitors treatment in the same period (19).

\section{Conclusion}

When child emergency applications are considered, UGB is a rare but very serious clinical condition that can be mortal. If the source of bleeding is especially esophageal varices or $\mathrm{PU}$, progression can be life-threatening and endoscopic interventions and ET may be required in these patients. The length of hospital stay in these patients is also longer. Determining risk factors, appropriate medication, close follow-up, early endoscopy, endoscopic or surgical intervention, if necessary, is important for reducing mortality.

\section{Authors' contributions}

EP designed the study, collected all data, wrote the manuscript, gained ethical approval; NAB collected and analyzed data, wrote the manuscript; GK collected data and supervised manuscript preparation, HAC collected data and searced literature. All authors reviewed and edited the manuscript and approved the final version of the manuscript.

\section{Ethical Issues}

Ethics committee approval was granted in 2017 (Number: B.10.1.THK. 3.33.J.GP.0.01). Each stage of the study was conducted in accordance with the ethical standarts and complies with the 1964 Helsinki Declaration. Additiaonally, a signed consent form was obtained from all participants.

\section{Availability of data}

The datasets analysed during this study are available from Nevzat Aykut Bayrak.

\section{References}

1. Poddar U. Diagnostic and therapeutic approach to upper gastrointestinal bleeding. Paediatr Int Child Health 2019; 39(1): 18-22. doi: 10.1080/20469047.2018.1500226.

2. Grimaldi-Bensouda L, Abenhaim L, Michaud L, Mouterde O, Jonville-Béra AP, Giraudeau B, et al. Clinical features and risk factors for upper gastrointestinal bleeding in children: a case-crossover study. Eur J Clin Pharmacol 2010; 66: 8317. doi: 10.1007/s00228-010-0832-3.

3. Colle I, Wilmer A, Le Moine O, Debruyne R, Delwaide J, Dhondt E, et al. Upper gastrointestinal tract bleeding management: Belgian guidelines for adults and children. Acta Gastroenterol Belg 2011; 74: 45-66.

4. Owensby S, Taylor K, Wilkins T. Diagnosis and management of upper gastrointestinal bleeding in children. J Am Board Fam Med 2015; 28(1): 134-45. doi: 10.3122/ jabfm.2015.01.140153.

5. Romano C, Oliva S, Martellossi S, Miele E, Arrigo S, Graziani MG, et al. Pediatric gastrointestinal bleeding: Perspectives from the Italian Society of Pediatric Gastroenterology. World J Gastroenterol 2017; 23(8): 1328-37. doi: 10.3748/ wjg.v23.i8.1328.

6. Banc-Husu AM, Ahmad NA, Chandrasekhara V, Ginsberg GG, Jaffe DL, Kochman ML, et al. Therapeutic endoscopy for the control of nonvariceal upper gastrointestinal bleeding in children: a case series. J Pediatr Gastroenterol Nutr 2017; 64(4): e88-e91. doi: 10.1097/mpg.0000000000001457.

7. Tringali A, Thomson M, Dumonceau JM, Tavares M, Tabbers MM, Furlano R, et al. Pediatric gastrointestinal endoscopy: European Society of Gastrointestinal Endoscopy (ESGE) and European Society for Paediatric Gastroenterology Hepatology and Nutrition (ESPGHAN) Guideline Executive summary. Endoscopy 2017; 49(1): 8391. doi: 10.1055/s-0042-111002.

8. Jafari SA, Kiani MA, Kianifar HR, Mansooripour M, Heidari E, Khalesi M. Etiology of gastrointestinal bleeding in children referred to pediatric wards of Mashhad hospitals, Iran. Electron Physician 2018; 10(2): 6341-5. doi: $10.19082 / 6341$.

9. Gimiga N, Olaru C, Diaconescu S, Miron I, Burlea M. Upper gastrointestinal bleeding in children from a hospital center of Northeast Romania. Minerva Pediatr 2016; 68(3): 189-95.

10. Cleveland K, Ahmad N, Bishop P, Nowicki M. Upper gastrointestinal bleeding in children: an 11-year retrospective endoscopic investigation. World J Pediatr 2012; 8(2): 123-8. doi: 10.1007/s12519-012-0350-8.

11. Kalyoncu D, Urganci N, Cetinkaya F. Etiology of upper gastrointestinal bleeding in young children. Indian J Pediatr 2009; 76(9): 899-901. doi: 10.1007/s12098-009-0195-x.

12. Gultekingil A, Teksam O, Gulsen HH, Ates BB, SaltikTemizel IN, Demir H. Risk factors associated with clinically significant gastrointestinal bleeding in pediatric ED. Am J Emerg Med 2018; 36(4): 665-8. doi: 10.1016/j. ajem.2017.12.022.

13. Mouterde O, Hadji S, Mallet E, Le Luyer B, Métayer P. Les hémorragies digestives chez l'enfant: a propos de 485 endoscopies. Ann Pediatr (Paris) 1996; 43(3): 167-76.

14. Usta M, Urganci N. Upper gastrointestinal bleeding in children: the role of helicobacter pylori infection and nonsteroidal anti-inflammatory drug use. West Indian Med J 2015; 64(2): 113-6.

15. Singhi S, Jain P, Jayashree M, Lal S. Approach to a child with upper gastrointestinal bleeding. Indian J Pediatr 2013; 80(4): 326-33. doi: 10.1007/s12098-013-0987-x.

16. Kim SJ, Oh SH, Jo JM, Kim KM. Experiences with endoscopic interventions for variceal bleeding in children with portal hypertension: a single center study. Pediatr Gastroenterol Hepatol Nutr 2013; 16(4): 248-53. doi: 10.5223/pghn.2013.16.4.248.

17. Nasher O, Devadason D, Stewart RJ. Upper gastrointestinal bleeding in children: a tertiary united kingdom children's hospital experience. Children (Basel) 2017; 4(11). doi: 10.3390/children4110095.

18. Zheng W, Jiang L, Jia X, Long G, Shu X, Jiang M. Analysis of risk factors and development of scoring system to predict severity of upper gastrointestinal bleeding in children. J Gastroenterol Hepatol 2019; 34(6): 1035-41. doi: 10.1111/ jgh.14548.

19. Attard TM, Miller M, Pant C, Kumar A, Thomson M. Mortality associated with gastrointestinal bleeding in children: a retrospective cohort study. World J Gastroenterol 2017; 23(9): 1608-17. doi: 10.3748/wjg.v23.i9.1608. 